\title{
Estratégia de gestão de múltiplos canais de distribuição: um estudo na indústria brasileira de alimentos
}

\author{
Vivian-Lara dos Santos Silva a*, Roberta de Castro Souza ${ }^{b}$, \\ Anne Aparecida Porto da Silva ${ }^{c}$, Maria Sylvia Macchione Saes ${ }^{d}$ \\ a*vivianlara@usp.br, FZEA/USP, Brasil \\ brobertacsouza@usp.br, POLI/USP, Brasil \\ canne.porto@gmail.com, FZEA/USP, Brasil \\ dssaes@usp.br, FEA/USP, Brasil
}

\section{Resumo}

Este artigo tem como objetivo investigar a gestão de canais múltiplos de distribuição realizada por relevantes indústrias brasileiras de alimentos. Para tal, foi conduzido estudo exploratório em dois estágios: referindo-se à condução de entrevistas a distância com gestores da área de suprimentos (junto a seis empresas), seguidas de entrevistas presenciais (em duas empresas selecionadas da amostra inicial). Independentemente do porte ou segmento de atuação, o estudo evidencia a busca por parte do elo processador de distribuir seus produtos por meio da combinação de dois formatos de varejo (grande e pequeno/médio) com, ao menos, mais um canal, com tendência positiva ao emprego de formatos alternativos, entre os quais o marketing direto. Corroborando a premissa central do estudo, a percepção dos entrevistados é que a gestão de múltiplos canais revela-se estratégica para o elo processador ao permitir atenuar o maior poder comparativo do grande varejo, dada a possibilidade de maior cobertura de mercado, customização nas vendas e melhor atendimento dos anseios dos consumidores.

Palavras-chave

Estratégia. Canal de distribuição. Poder. Varejo. Indústria de alimentos.

\section{Introdução}

Nos anos 80, pouco sentido fazia falar em poder do varejo. 0 comerciante tinha que aceitar a política de venda do fornecedor (segmento processador). Condições de pagamento e de como, onde e quando a mercadoria seria entregue não costumavam ser negociadas, mas previamente estabelecidas pela firma processadora e "acatadas" pelo segmento varejista. A partir de meados da década de 1990, porém, a história começou a tomar outros rumos, passando as redes varejistas (em particular grandes redes) a deter as rédeas dos canais de distribuição (Rosenbloom, 2004; Bowersox et al., 2007).

Procurando ilustrar a relevância dessa discussão, pode ser considerado o caso europeu. No final da década de 1990, os dez primeiros grupos varejistas com atuação na Europa detinham 34\% das vendas totais, enquanto as dez principais firmas de bens de consumo detinham $14 \%$ das vendas no continente (Gurdjian et al., 2000).

A inversão no controle dos canais de distribuição passando o elo varejista a desfrutar de uma situação comparativamente mais confortável com relação ao segmento processador também seguiu-se no Brasil. Inversão no setor varejista brasileiro que, segundo Aguiar (2009) e Aguiar e Figueiredo (2011), pode ser dividida em dois períodos. 0 primeiro, compreendido entre os anos de 1994 a 1999, foi marcado pelo aumento da concentração do setor (realidade também verdadeira em termos do varejo mundial); fase seguida pelo segundo período, entre 2000 e 2008, quando foi registrada a estabilização da concentração das cinco maiores empresas varejistas 
no país. Diante dessa inversão no controle dos canais, como devem se comportar os outros membros do canal? Questionamento que o presente artigo direciona particularmente à indústria brasileira de alimentos.

A literatura apresenta algumas possiveis respostas a esse questionamento, respeitando a ênfase aqui assumida (da indústria de alimentos). Coughlan et al. (2001) destacam cinco possíveis respostas do segmento processador ao poder crescente do setor varejista. A primeira delas seria assumir maior controle sobre os fluxos do canal, em termos do desenvolvimento de novas tecnologias como, por exemplo, de gerenciamento de demanda e de estoques. Os fluxos de canal são intrínsecos ao relacionamento de seus membros (fabricantes, intermediários e usuários finais), independentemente da estrutura observada em termos da extensão por meio da qual se dá a distribuição. A questão central é quem coordenará os fluxos, os quais usualmente classificados como: de posse física/propriedade, de comunicação/promoção, de informação, de negociação, monetário e de produto. A problemática se materializa na medida em que se pode eliminar ou substituir os membros do canal, mas os fluxos desempenhados por esses membros não podem ser eliminados (Kotler, 2000; Coughlan et al., 2001; Rosenbloom, 2004; Bowersox et al., 2007).

Outras opções tratadas por Coughlan et al. (2001) em decorrência do maior poder comparativamente do elo varejista no controle dos canais de distribuição referem-se a modificar o papel das promoções de preço no composto total de marketing, expandir a linha de produto, além de despojar as funções que não sejam de marketing e redirecionar essas despesas.

Uma última opção (estratégia) discutida por Coughlan et al. (2001), foco de interesse deste artigo, reporta-se à expansão do número de canais de marketing, aqui tratada como estratégia de canais múltiplos. Em seu caráter pragmático, o artigo investiga a gestão de canais múltiplos de distribuição realizada por relevantes indústrias brasileiras de alimentos.

Para Kotler (2000) e Bowersox et al. (2007), a proliferação dos segmentos de clientes e as inúmeras possibilidades de canal vêm estimulando a decisão organizacional por canais múltiplos de distribuição. As vantagens trazidas pelos canais múltiplos diriam respeito à maior cobertura de mercado, custo reduzido de canal, além de vendas mais personalizadas. Coughlan et al. (2001), por sua vez, analisam o crescimento no uso de canais múltiplos em função do aumento da concorrência, o que levaria os fornecedores a modificarem seus canais de distribuição. É mais difícil atender os clientes por meio de um único tipo de canal em um mercado cada vez mais fragmentado. A escolha de canais múltiplos é vantajosa para os fornecedores, pois podem aumentar a penetração no mercado e criar barreiras para a entrada de concorrentes. Os clientes gostam de canais múltiplos, pois dessa forma podem encontrar um canal que atenda às suas demandas (Coughlan et al., 2001). Por fim, esses mesmos autores ressaltam o papel dos avanços tecnológicos na decisão organizacional pela gestão de múltiplos canais.

Face a essa discussão, a proposição defendida neste artigo é que a gestão de múltiplos canais se revela estratégica para a indústria de alimentos ao permitir atenuar o maior poder comparativo do grande varejo na coordenação dos canais de distribuição, dada a possibilidade de maior cobertura de mercado, customização nas vendas e melhor atendimento dos anseios dos consumidores (Kotler, 2000; Coughlan et al., 2001).

0 artigo é estruturado em três seções, em acréscimo a esta introdução, e das considerações finais. A discussão é iniciada por meio do resgate da compreensão do conceito de canais de distribuição, tratando ainda de seus integrantes e funções; seguindo-se da análise de como algumas das principais tendências registradas no setor varejista vêm favorecendo o crescente maior poder do grande varejo no controle dos canais de distribuição. Feita a revisão do debate teórico, o artigo segue com a apresentação do método utilizado, seguindo-se da discussão dos principais resultados obtidos no estudo exploratório realizado em dois estágios (entrevistas presenciais e a distância). Em síntese, por meio de entrevistas a distância, conduziu-se no primeiro estágio o mapeamento dos canais de distribuição empregados por seis empresas, analisando-se complementarmente a relação estabelecida com o elo varejista, em especial com as grandes redes (prós e contras do relacionamento estabelecido sob a perspectiva da indústria). Por fim, no segundo estágio do estudo exploratório, realizou-se uma investigação aprofundada da decisão organizacional da estratégia de múltiplos canais por meio da condução de estudo multicaso, a partir da análise de duas empresas selecionadas da amostra inicial (entrevistas presenciais).

\section{Conceito, integrantes e funções dos canais de distribuição}

De acordo com revisão encontrada em Silva et al. (2012a), uma das mais importantes decisões com que se depara o segmento processador refere-se a como organizar seus canais de distribuição. 0 tópico canais de distribuição é um dos mais antigos na literatura sobre marketing, sendo até considerado uma de suas vertentes originais (Kotler, 1972). Mais recentemente, diversos autores tratam-no de maneira 
ampla, denominando-os classicamente de "canais de distribuição" (marketing/distribution channels).

As diferentes definições de canais de distribuição (Stern et al., 1996; Berman, 1996; Coughlan et al., 2001; Rosenbloom, 2004) convergem para a interpretação de grupos de empresas interdependentes com a responsabilidade de disponibilizar no mercado um produto ou serviço para uso ou consumo. Canais de distribuição podem, assim, ser entendidos como todas as movimentações técnico-econômico-financeira existentes desde a matéria-prima, passando por sua transformação industrial (em diferentes níveis), seguidas de sua distribuição/comercialização até propriamente o uso/consumo pelo usuário final.

Nesse sentido, Coughlan et al. (2001) definem canais de distribuição como: um conjunto de organizações interdependentes envolvidas no processo de disponibilizar um produto ou serviço para uso ou consumo. Cada membro é dependente de outro membro do canal para desempenhar sua função e fazer um canal de distribuição funcionar. 0 relacionamento com o cliente, na maioria das vezes, não termina com a efetuação da venda do produto e todos os membros devem concentrar sua atenção no usuário final. A finalidade do canal de distribuição é satisfazer os usuários finais do mercado. 0 principal objetivo é fazer com que os clientes utilizem ou consumam o produto ou serviço que está sendo vendido.

Para ser membro de determinado canal é necessário desempenhar atividades que contribuam com agregação de valor do produto para os usuários finais (Coughlan et al., 2001). Os principais membros do canal de distribuição são produtores e fabricantes intermediários (contemplando especialistas, atacadistas e varejistas) e usuários finais (consumidores individuais ou clientes de empresas).

Rosenbloom (2004) descreve produtores e fabricantes como todas as empresas que trabalham na extração, cultivo ou fabricação de produtos, englobando todos os portes de empresa, desde a multinacional até microempresas. 0 principal objetivo de produtores e fabricantes é oferecer produtos que satisfaçam às necessidades dos mercados, mas para chegar a esse ideal é necessário disponibilizar os produtos ao consumidor final. No entanto, grande parte dos produtores e fabricantes, mesmo os de grande porte, não se interessa pela execução direta da atividade de distribuição, em função dos maiores custos esperados (Rosenbloom, 2004), responsabilidade, nesse contexto, delegada aos "intermediários" do canal (especialistas, atacadistas e varejistas).

No que se refere aos intermediários da classe "especialistas", Rosenbloom (2004) considera que elas se tratam, em sua maioria, de empresas prestadoras de serviços, oferecendo assistência na distribuição dos produtos, exceto na compra, venda e transferência de direitos. Essas empresas podem não atuar dentro do canal de distribuição, mas são contratadas para a melhoria do trabalho de distribuição. Procurando ilustrar essa classe de membros, tem-se os operadores logísticos, desempenhando funções de transporte, armazenagem e/ou processamento de pedidos, bem como agências de publicidade e propaganda, instituições financeiras, seguradoras, empresas de pesquisa de marketing, de cartões de crédito e empresas de tecnologia da informação.

Quanto à classe dos intermediários denominados "atacado", Rosenbloom (2004) descreve como empresas que vendem bens para a revenda, uso comercial, industrial (mercado business to business) ou institucional, referindo-se às creches, hospitais e escolas, por exemplo. 0 atacadista não vende para usuários finais individuais, portanto suas vendas restringem-se a membros intermediários e para usuários finais de empresa (Coughlan et al., 2001).

Segundo Coughlan et al. (2001), na categoria atacadistas estão incluídos os chamados distribuidores ou também atacadistas comerciais. Esses assumem a

[...] titularidade e a posse física do estoque, armazenam estoques, promovem os produtos em sua linha e negociam financiamento, pedido e pagamento com seus clientes. (Coughlan et al., 2001, p. 29).

Ainda na categoria atacadistas há os chamados agentes dos fabricantes, corretores e representantes comissionados que são classificados de acordo com as atividades de distribuição que assumem. Segundo Rosenbloom (2004), as principais tarefas de distribuição são: (1) apresentar os produtos do contratante aos clientes do mercado local; (2) contatar o varejista regularmente para verificar se os produtos do contratante estão sendo distribuídos e dispostos nas prateleiras conforme acordado; (3) coordenar atividades promocionais com os varejistas; (4) fornecer informações de mercado ao contratante; (5) garantir que os pedidos dos produtos do contratante estão sendo feitos corretamente, bem como os recebimentos e controle dos itens vendidos e descartados.

Tendo em vista as tarefas de distribuição, os agentes dos fabricantes são aqueles contratados para desempenhar as atividades de cobertura de mercado e contato de vendas. Já os corretores podem desempenhar a maioria das atividades de distribuição, a depender do contrato que estabelecem com o contratante e seu nível de especialização nas diferentes atividades de distribuição. Por fim, o representante comissionado pode ser contratado tanto por produtores quanto fabricantes. Os representantes recebem e armazenam a mercadoria, atuam estendendo crédito 
pessoal, processam pedidos e também podem atuar organizando as entregas. Como atuam diretamente na venda, também recebem do cliente e repassam o dinheiro para o fabricante ou produtor já deduzido o valor de sua comissão pelo serviço prestado. Vale ressaltar que, por vezes, os produtores ou fabricantes passam anônimos aos compradores (Rosenbloom, 2004). As definições de corretores e representantes comissionados são bastante similares ao conceito de broker, que é bastante popular entre os agentes do mercado, como indústrias e varejistas. Observa-se que o broker pode assumir mais ou menos atividades de distribuição a depender de seu grau de especialização.

Por fim, para Kotler (2000), a última categoria de intermediários, denominada "varejo", inclui todas as atividades relativas à venda de produtos ou serviços diretamente aos consumidores finais, para uso pessoal e não-comercial. 0 varejo atua na venda de produtos para consumo pessoal ou doméstico e na prestação de serviços ligados à venda de bens (Rosenbloom, 2004). Qualquer organização que se enquadra nesse posicionamento, seja ela fabricante, atacadista ou varejista, está, portanto, praticando varejo (Rosenbloom, 2004), não importando:

a maneira pela qual os bens ou serviços são vendidos (venda pessoal ou a distância, por mala direta ou catálogo, via Correios, internet, ou telefone);

o local da comercialização (em lojas, na rua, ou diretamente na residência dos consumidores, referindo-se à modalidade de vendas diretas, ou marketing direto);

a localização do consumo (na residência ou fora do lar, reportando-se ao segmento de food service);

a forma de gestão da marca e do sistema de negócio (seja verticalizado ou delegado a terceiros, no formato de franchising ou licenciamento de marca, por exemplo).

São exemplos de varejistas lojas de departamentos, lojas de conveniência, franquias, redes de estabelecimentos, clubes de compras, clubes de armazéns e varejistas on-line (Coughlan et al., 2001). Pode-se ainda considerar mercearias e mercados em geral, classificação que remete à distinção do tamanho dos estabelecimentos. Seguindo definição empregada por Nielsen visto em Revista SuperHiper (1996), classifica-se como "grande varejo" estabelecimentos a partir de 20 checkouts; "médio varejo", de cinco a 19 checkouts; e "pequeno varejo", de um a quatro.

\section{Inversão do controle do canal: no comando, o varejo}

A forma que o canal assume para realizar a transferência de propriedade de produtos e serviços é entendida como a estrutura do canal, a ser definida em função da extensão do número de organizações envolvidas nas transações de troca durante o processo de comercialização, do fornecedor inicial até o comprador final. Tecnicamente, a extensão da estrutura do canal de distribuição refere-se ao número de níveis que o canal apresenta. Pode variar de dois níveis, no caso de o fabricante ou produtor responsabilizar-se pela venda de seus produtos/serviços ao consumidor final (vendas diretas), a três ou mais níveis, quando o fabricante se vale dos membros intermediários, a exemplo do atacado e varejo (Bowersox \& Closs, 2001).

Vários fatores como consumidores, tipos de produtos comercializados e porte do fornecedor ou cliente podem afetar a extensão e, consequentemente, a estrutura dos canais. Os consumidores influenciam por seu tamanho, sua localização geográfica e seus padrões de comportamento. Os tipos de produto, por sua vez, exercem influência por seu volume, peso, perecibilidade, valor e complexidade técnica. Enquanto o porte do fornecedor ou do cliente influenciam na relação de controle do canal, pois quanto mais economicamente fortes eles forem, maior a capacidade de eliminar possíveis intermediários e encurtar sua estrutura (Pêgo, 2009).

Nesse sentido, entre os fatores que vêm beneficiando a transferência do poder dos canais de distribuição das mãos da indústria para o setor varejista tem-se a estratégia de verticalização a jusante (crescimento, por exemplo, obtido pela aquisição de "bandeiras" concorrentes), culminando na expressiva concentração que marcou mundialmente o varejo nas últimas décadas, processo também registrado no Brasil (Reardon et al., 2007, 2010; Aguiar \& Figueiredo, 2011). Particularmente no caso do mercado brasileiro, a concentração do setor varejista vem sendo disputada por três empresas: Pão de Açúcar, Carrefour e Walmart (Aguiar \& Figueiredo, 2011). A Tabela 1 procura retratar a evolução registrada no período entre 2005 e 2010.

Somado a esse processo de concentração do setor varejista, Bell et al. (1997) discutem a estratégia do varejo de internalizar as funções tradicionalmente exercidas pelos atacadistas, por meio de investimentos em depósitos de distribuição (outro caso de estratégia de verticalização a jusante). Alcântara (1999) também se interessa pela atuação do varejo, particularmente com a questão da reação dos atacadistas face o maior poder detido pelas grandes redes, chamadas de power buyers nos Estados Unidos. Um exemplo de power buyer é o varejista Walmart. Segundo Rosembloom e Mollenkopf (1993), citado por Alcântara (1999), uma das características do grande varejo (power buyer) é a atuação em larga escala e o fato de deter substancial poder no canal. 
Tabela 1. Evolução do processo de concentração registrado no varejo alimentar brasileiro.

\begin{tabular}{|c|c|c|c|c|c|c|}
\hline \multirow{2}{*}{ Rede } & \multicolumn{6}{|c|}{ Faturamento (R\$/bilhões) } \\
\hline & 2005 & 2006 & 2007 & 2008 & 2009 & 2010 \\
\hline Pão de Açúcar & $\begin{array}{c}15,8 \\
\text { (Em 2005, a } \\
\text { cadeia francesa } \\
\text { Casino amplia sua } \\
\text { participação no } \\
\text { grupo brasileiro, } \\
\text { originando a } \\
\text { holding Vieri.) }\end{array}$ & 16,1 & $\begin{array}{c}18,8 \\
\text { (0 grupo adquire } \\
60 \% \text { do capital } \\
\text { da rede atacadista } \\
\text { Assai.) }\end{array}$ & 20,9 & $\begin{array}{c}26,2 \\
\text { (Com a compra } \\
\text { em junho de } \\
2009 \text { da Globex } \\
\text { Utilidades, } \\
\text { dona da rede } \\
\text { Ponto Frio, o } \\
\text { Grupo Pão de } \\
\text { Açúcar recupera } \\
\text { a liderança no } \\
\text { varejo brasileiro.) }\end{array}$ & $\begin{array}{c}36,1 \\
\text { (Com a aquisição } \\
\text { das Casas Bahia, } \\
\text { o Grupo Pão de } \\
\text { Açúcar vende 38\% } \\
\text { mais em 2010.) }\end{array}$ \\
\hline Carrefour & 12,5 & 12,6 & $\begin{array}{c}19,3 \\
\text { (Com a aquisição } \\
\text { da rede Atacadão, } \\
\text { o grupo francês } \\
\text { retorna, após sete } \\
\text { anos, à liderança } \\
\text { do setor varejista.) }\end{array}$ & 22,5 & 25,6 & 29,0 \\
\hline Walmart & 11,7 & $\begin{array}{c}12,9 \\
\text { (Em 2006, o } \\
\text { grupo americano } \\
\text { inverte o jogo, } \\
\text { roubando do } \\
\text { Carrefour a } \\
\text { segunda posição } \\
\text { no ranking } \\
\text { brasileiro.) }\end{array}$ & 15,0 & $\begin{array}{c}16,9 \\
\text { (0 Walmart } \\
\text { investe } \mathrm{R} \$ \\
1,2 \text { bilhão na } \\
\text { expansão da rede } \\
\text { no Brasil em } \\
\text { 2008.) }\end{array}$ & 19,7 & 22,3 \\
\hline
\end{tabular}

Fonte: ABRAS, visto em Marsola (2008), Silva et al. (2012b), Kamio (2010).

Já no Brasil, evidências apontam para a realização de investimentos por parte das grandes redes varejistas em centrais de compra, referindo-se à estratégia de verticalização a montante (Faulin \& Azevedo, 2003), a partir da qual o varejo passa a exercer maior poder de compra junto a seus fornecedores pelo aumento da escala (Souza, 2001).

0 maior poder dos varejistas dentro dos canais de distribuição, por meio da internalização (verticalização) das operações comerciais e financeiras, seja a montante, seja a jusante, confere-lhes a possibilidade de redução de custos e aumento de sua margem de lucro. A escolha pela verticalização possibilita à firma integradora um maior domínio sobre diferentes níveis do canal de distribuição e, portanto, maior controle sobre ações neles conduzidas. Dessa forma viabiliza-se uma maior eficiência na coordenação e gerenciamento da produção e/ou distribuição, trazendo vantagens como ganhos de poder pelo aumento do negócio, eliminação da barganha e racionalização de estoques (Silva et al., 2009). Para Faulin \& Azevedo (2003), a centralização da compra de produtos por meio de centrais de compra confere aos grandes varejistas redução de custos da ordem de 30\%.

Adicionalmente, Rosenbloom (2004) destaca a estratégia de os varejistas como "leões de chácara" nos mercados de consumo, atuando como agentes de compra para clientes e não como agentes de venda para fornecedores. As lojas não crescem em tamanho tão rápido quanto o ritmo de lançamento de novos produtos, assim os varejistas têm muitos produtos novos para escolher ao decidir o que estocar em suas prateleiras e a posição de barganha dos fornecedores enfraquece (Coughlan et al., 2001).

Soma-se a isso o fato de os varejistas se beneficiarem das informações "canalizadas" sobre os hábitos dos consumidores para coordenar as cadeias que os abastecem. Não bastasse, avanços em Tecnologia da Informação (TI) também vêm favorecendo o maior poder do varejo (Bowersox et al., 2007). Tome-se como exemplo a estratégia de gerenciamento de categorias (Bell et al., 1997; Marques \& Alcantara, 2004). 0 gerenciamento de categorias é um sistema cujo objetivo é reduzir a distância entre fornecedor e cliente por meio da definição e gerenciamento de categorias de produtos ao invés de marcas individuais. A ideia principal é que esse gerenciamento ocorra em um ambiente de confiança mútua e cooperação entre indústria e varejo (Hutchins, 1997). No entanto, esse sistema acabou por diminuir o poder da indústria ao conferir aos varejistas a capacidade de gerenciar marcas a distância e manter a indústria cada vez mais distante da atividade de gerenciamento da marca (Hutchins, 1997).

Adicionalmente, fator relevante reside na crescente dificuldade e no alto custo que os fabricantes 
enfrentam no desenvolvimento de novos produtos (Bowersox et al., 2007) bem como na comercialização (Noll, 2005).

Por um lado, a estratégia de marcas próprias dos varejistas tende a apresentar maior penetração no mercado quando comparada às marcas dos fabricantes (Bowersox et al., 2007). Estima-se que no Reino Unido, França e Alemanha a penetração de marcas próprias aumentou cerca de dez pontos entre 1980 e 1990. No caso do Reino Unido, o nível de penetração de marcas próprias é o mais alto, com 45\% (Bell et al., 1997). No tocante à Inglaterra, especificamente - país pioneiro nessa estratégia (Berman, 1996) -, a participação de mercado das marcas próprias em alimentos e bebidas chega a 50\% (Mintel, 2006). No Brasil, por sua vez, a estratégia de marcas próprias vem sendo consolidada nas últimas décadas, conforme análise de Paula et al. (2012). Apesar de comparativamente incipiente no país, os mesmos autores atribuem como ganhos do emprego de marcas próprias vantagens competitivas, de marketing (imagem do varejista) e de negociação, em decorrência de maior controle sobre os preços de venda, auferindo maiores margens de lucro.

Por outro lado, parece natural assumir ser mais barato usar o mercado (varejo) comparativamente à decisão organizacional do elo processador em internalizar (verticalizar) a comercialização direta de seus produtos, sobretudo se por meio de (redes de) lojas. De fato, o aumento do poder comparativo do varejo na coordenação dos canais vem sendo também interpretado sob a óptica das economias que o uso do varejo confere ao elo processador, a exemplo da redução de custos de transação e de agência (controle e monitoramento da força de vendas, por exemplo) (Noll, 2005).

Fortalecido nas últimas décadas, em decorrência de todo o quadro discutido até aqui, o setor varejista teria passado a estabelecer práticas contratuais criticadas pelo segmento de processamento industrial (Fleury, 1999). De fato, baseadas em contratos de longo prazo, além da imposição de condições de preço, pontualidade na entrega e qualidade dos produtos, tornaram-se praxe no setor exigências de descontos para lançamentos, na vinculação de promoções, nas vendas em datas especiais, além de cobrança pela utilização de posição privilegiada (pontas de gôndola) e do chamado "enxoval", mercadorias gratuitamente fornecidas para a rede na inauguração das lojas (Silva et al., 2012b; Alcantara, 1997; Dobson, 2003).

Colocado o problema com que se depara a indústria, quais seriam as possíveis estratégias desse segmento para enfrentar a perda de poder para o varejo no controle dos canais de distribuição? Entre outras proposições discutidas na literatura de varejo (Coughlan et al., 2001), o presente artigo investiga a estratégia de canais múltiplos.

\section{Resultados e discussão: a estratégia de canais múltiplos como alternativa da indústria de alimentos}

Face os objetivos do presente artigo, optou-se pela condução de um estudo exploratório em dois estágios, referindo-se à condução de entrevistas a distância, primeiro estágio, seguidas de entrevistas presenciais, segundo estágio, junto a gestores (gerentes e diretores) da área de suprimentos de indústrias de alimentos com atuação no mercado brasileiro. 0 objetivo do primeiro estágio foi mapear os principais canais de distribuição empregados pela indústria brasileira de alimentos, assim como levantar a percepção dos entrevistados a respeito das vantagens e dos desafios relacionados ao grande varejo. Os resultados obtidos no primeiro estágio da pesquisa foram empregados na escolha das empresas alvo da continuidade do estudo exploratório, por meio da condução do estudo multicaso (segundo estágio). 0 recorte para decisão das empresas que seriam alvo dos estudos de caso se deu na experiência de gestão de diferentes canais de distribuição, tendo sido o critério de escolha a atuação no marketing direto (um dos resultados obtidos na pesquisa em termos da atratividade de novos canais de distribuição). As empresas selecionadas responderam a um segundo questionário, presencial, que buscou aprofundar a análise da escolha organizacional pela estratégia de múltiplos canais.

\section{Primeiro estágio do estudo: mapeamento da estratégia de canais múltiplos e a percepção do relacionamento com o grande varejo}

0 intuito do primeiro estágio do estudo foi a coleta de informações gerais sobre a estratégia de múltiplos canais por parte da indústria de alimentos como estratégia de resposta desse setor ao maior poder comparativamente do grande varejo, norteando a confecção de um roteiro de entrevistas estruturado em duas partes. Na primeira, composta por questões fechadas, procurou-se mapear a representatividade dos canais de comercialização empregados pelas empresas analisadas em termos de faturamento total. $\mathrm{Na}$ segunda parte do questionário, o objetivo foi entender o modo como é formalizada a relação com o grande varejo, assim como levantar a percepção das empresas sobre as vantagens e desvantagens no relacionamento com esse canal.

0 convite foi direcionado aos gestores (diretores e gerentes) da área de suprimentos, por meio do envio, eletrônico, do questionário, juntamente à carta de apresentação da equipe e dos interesses 
da investigação, abordagem sempre precedida de contato telefônico. Visando melhor sensibilizar os contatados, inclusive sobre a seriedade e a qualidade da pesquisa, de forma a repercutir na participação de um maior número de empresas de interesse, buscou-se a concepção de um questionário de qualidade visual (agradável e amigável) e de conteúdo objetivo e sucinto. A troca de comunicação e a coleta de dados deram-se entre os meses de outubro e novembro de 2010.

Conforme compilado na Tabela 2, seis empresas aceitaram participar do estudo. Dessas, quatro empresas encontram-se entre as maiores do Brasil, conforme o Ranking Exame 2010. 0 artigo não relaciona as respectivas posições no ranking a fim de preservar as identidades das empresas (referenciadas na Tabela 2 como empresas A, B, C e D), atendendo a exigência feita como condição para participarem da análise. Aceitaram ainda participar da pesquisa outras duas empresas (empresas E e F, na Tabela 2) não classificadas no Ranking Exame 2010. A participação dessas empresas na pesquisa buscou evidenciar que a busca por canais alternativos de distribuição não está relacionada à escala industrial. Com menor poder de negociação frente às imposições do grande varejo, as pequenas e médias empresas também devem optar por escoar seus produtos através de canais múltiplos.

A Tabela 2 sinaliza a estratégia de canais múltiplos empregada pelas empresas analisadas no primeiro estágio do estudo exploratório conduzido, distinguindo-as em termos de sua representatividade (faturamento declarado pelas empresas). Sendo a amostra pequena e estatisticamente não representativa, as evidências levantadas pelo estudo devem ser entendidas como proposições a serem testadas em trabalhos futuros, não podendo ser generalizadas. A despeito dessa importante ressalva, o estudo exploratório evidencia cinco principais resultados: i) disseminação da estratégia de canais múltiplos; ii) relevância do grande e do pequeno/médio varejos no escoamento dos produtos; iii) tendência de maior representatividade de canais alternativos; e v) atratividade do emprego do canal direto.

\subsection{Primeiro resultado: disseminação da estratégia de múltiplos canais}

Independentemente do porte ou segmento de atuação, o estudo evidencia a busca por parte da indústria em distribuir seus produtos por meio de mais de um canal. 0 estudo revela que todas as empresas conciliam no mínimo de três canais de distribuição. A esse respeito, na amostra considerada, a empresa $\mathrm{C}$ se revelou a que utiliza a maior combinação (em números) de formatos de distribuição, atuando concomitantemente em seis
Tabela 2. Indústrias de alimentos e estratégia de canais múltiplos.

\begin{tabular}{|c|c|}
\hline Empresa* & $\begin{array}{c}\text { Canais adotados } \\
\text { ( } \% \text { faturamento total declarado) }\end{array}$ \\
\hline A & $\begin{array}{l}\text { Grandes redes } 82 \% \\
\text { Pequeno e médio varejo 13\% } \\
\text { Food service 5\% }\end{array}$ \\
\hline \multirow{4}{*}{ B } & Atacado $46 \%$ \\
\hline & Pequeno e médio varejo 35\% \\
\hline & $\begin{array}{l}\text { Grandes redes } 15 \% \\
\text { Food service } 2 \%\end{array}$ \\
\hline & Farmácias 2\% \\
\hline \multirow{4}{*}{$\mathrm{C}$} & $\begin{array}{l}\text { Pequeno e médio varejo } 61 \% \\
\text { Grandes redes } 27 \%\end{array}$ \\
\hline & $\begin{array}{l}\text { Atacado } 9 \% \\
\text { Food service } 2 \%\end{array}$ \\
\hline & Mercado institucional 0,5\% \\
\hline & Vendas diretas $0,5 \%$ \\
\hline \multirow{4}{*}{ D } & $\begin{array}{c}\text { Pequeno e médio varejo } 49,8 \% \\
\text { Grandes redes } 46 \%\end{array}$ \\
\hline & Atacado 3,6\% \\
\hline & Vendas diretas $0,5 \%$ \\
\hline & Mercado institucional 0,1\% \\
\hline \multirow{3}{*}{$E^{* *}$} & $\begin{array}{c}\text { Food service } 37,9 \% \\
\text { Grandes redes } 27,3 \% \\
\text { Pequeno e médio varejo } 26,2 \%\end{array}$ \\
\hline & Atacado $7,2 \%$ \\
\hline & Mercado institucional 1,4\% \\
\hline \multirow{3}{*}{$\mathrm{F}$} & Distribuidores $83,4 \%$ \\
\hline & Pequeno e médio varejo 9,6\% \\
\hline & Grandes redes $7,0 \%$ \\
\hline
\end{tabular}

diferentes canais. Por sua vez, as empresas B, D e E conciliam a gestão de cinco canais; enquanto as empresas A e F, três canais. De acordo com os gestores entrevistados, a decisão pela gestão de múltiplos canais de distribuição reside na complementaridade dos diferentes formatos. 1sso porque, a despeito da maior complexidade oriunda da gestão de múltiplos canais resultar tanto em maiores custos quanto em conflitos de interesses entre os canais, a estratégia plural de distribuição permite à indústria uma maior cobertura de mercado, contribuindo ainda para uma maior customização nas vendas e melhor atendimento dos anseios dos consumidores. Entendimento alinhado com a discussão de Kotler (2000) e Coughlan et al. (2001).

\subsection{Segundo resultado: ruim com ele (grande varejo), pior sem ele}

Examinando em detalhes a estratégia evidenciada de canais múltiplos, os resultados sugerem a relevância do setor varejista, em particular do grande varejo, no escoamento da produção industrial alimentícia. 
Por um lado, segundo percepção dos entrevistados, a principal vantagem apontada ao se comercializar com as grandes redes diz respeito ao volume que elas absorvem, disponibilizando produtos para um grande número de consumidores finais e proporcionando grande visibilidade para as marcas. De fato, como constatado pelo elo processador, ficar fora das gôndolas de uma das grandes redes varejistas pode representar a ausência em mais de 10\% do mercado nacional (Silva et al., 2012b), reforçando assim a imagem de vitrine que essas redes representam para esse segmento. Por outro lado, os gestores entrevistados apontam a prática por parte do grande varejo de condições impostas à indústria de alimentos quanto a prazo de pagamento, bem como de investimento em ações promocionais e inaugurações do varejo.

A Tabela 3 compila as vantagens e desvantagens sob a perspectiva da indústria de alimentos quanto à comercialização via grande varejo. Mesmo apesar do conflito embutido na percepção de todos os entrevistados, face as exigências cada vez maiores, conforme declaração registrada em todas as entrevistas (vide desvantagens, Tabela 3), os entrevistados, sem exceção, atestam: "a obrigatoriedade da indústria em perpetuar a relação contratual com o grande varejo, especificamente com os key accounts", em decorrência do que pode ser entendido como "retorno positivo" (vantagens) desse canal.

\subsection{Terceiro resultado: igual, mas diferente (vantagens pequeno/médio varejo)}

Além das grandes redes varejistas, os resultados corroboram a relevância do pequeno/médio varejo no escoamento dos produtos industriais. Esse canal é empregado por todas as empresas analisadas, estando sempre entre os canais de maior significância. De fato, o pequeno/médio varejo é o canal de maior relevância para as empresas $\mathrm{C}$ e $\mathrm{D}$, representando a segunda mais importante 'via de escoamento' para as empresas A, B e F e a terceira para a empresa E.

Esse resultado está de acordo com pesquisa que analisou as relações entre varejo e fornecedores de vegetais frescos e que evidenciou a importância do pequeno e médio varejo para o escoamento desses produtos na cidade de São Paulo (Souza \& Scur, 2011). A respeito desse resultado evidenciado no estudo, chama a atenção a possibilidade que o canal traz: de transformar o que seria seu grande ponto falho (pequena escala) em um poderoso trunfo em benefício da indústria de alimentos. Graças à maior proximidade entre consumidor e vendedor, estabelecimentos de menor porte, quando bem explorados, devem revelar-se mais eficientes na satisfação dos novos padrões de consumo. Vantagens competitivas importantes podem ser exploradas via a melhor identificação das preferências dos consumidores e, assim, a oferta de um serviço customizado, repercutindo em um maior valor na experiência de compra e na possibilidade de desfrutar do recebimento de um preço premium (Silva et al., 2009).

Corroborando essa discussão, pesquisa publicada pela Nielsen em fevereiro de 2010 mostra que o pequeno/médio varejo apresenta o maior crescimento de vendas no país. 0 levantamento reflete as vendas no varejo de 159 categorias de bens de consumo em 2009. A referida pesquisa indica que as lojas de autosserviço, com 20 a 49 checkouts, apresentaram um desempenho superior, estimado em 9,3\%, com relação ao ano de 2008. Crescimento expressivo também foi observado nos supermercados com cinco a nove checkouts: crescimento de 7\% em comparação ao desempenho de 2008. Em contraposição a essa evolução registrada no pequeno/médio varejo, no mesmo período, lojas com mais de 50 checkouts (grande varejo) registraram um declínio de 6,4\% nas vendas (Farina \& Nunes, 2002; Salles, 2010).

\subsection{Quarto resultado: aumento da representatividade de canais alternativos}

Não importando porte ou segmento da indústria, os resultados sugerem o emprego casado de dois diferentes formatos de varejo (grande e médio/ pequeno) com, no mínimo, um outro canal de distribuição. Buscando atenuar o poder das grandes

Tabela 3. Vantagens e desvantagens do grande varejo.

\begin{tabular}{|c|c|}
\hline Vantagens & Desvantagens \\
\hline Maior volume & Imposição de condições de prazo e de pagamento. \\
\hline Exposição da marca (varejo como vitrine) & Investimento em ações promocionais e inaugurações. \\
\hline $\begin{array}{l}\text { Impacto em market share (disponibiliza o portfólio de produtos para } \\
\text { um grande número de consumidores finais). }\end{array}$ & $\begin{array}{l}\text { Frequência de entrega, disponibilidade de produto na gôndola, baixo } \\
\text { nível de estoque e exigência de baixo nível de perdas por vencimento. }\end{array}$ \\
\hline $\begin{array}{l}\text { Facilidade para negociar promoções de interesse mútuo (gestão } \\
\text { colaborativa). }\end{array}$ & Pagamento de bonificações atreladas ao volume de compras/vendas. \\
\hline $\begin{array}{l}\text { Velocidade de introdução de novos produtos (lançamentos) para o } \\
\text { consumidor. }\end{array}$ & $\begin{array}{l}\text { Condições de logística específicas para cada cliente: tipo de veículo, } \\
\text { paletização, horário de entrega. }\end{array}$ \\
\hline Presença dos demais competidores do segmento. & Promotores que organizem e reabasteçam as gôndolas. \\
\hline
\end{tabular}


redes varejistas, os resultados trazem a estratégia declarada da indústria de alimentos pelo aumento da representatividade de canais alternativos, tanto em termos de vendas quanto de faturamento.

De fato, apenas para uma das empresas analisadas (empresa A), as grandes redes correspondem ao canal de maior significância. Essa mesma empresa, porém, concilia o grande e pequeno/médio varejo com outro canal, o food service. Esse resultado mais do que pontual sugere uma tendência observada entre as demais empresas investigadas. Os resultados evidenciam que o atacado e o food service são duas importantes "vias de escoamento" da indústria de alimentos, sendo que cada um deles está presente na estratégia de distribuição de quatro empresas entre as seis investigadas no estudo. 0 grau de relevância desses canais citados é variável, porém cada um deles representa o formato de distribuição de maior importância para uma das empresas dentro da amostra, sendo o atacado o canal mais significativo para a empresa B e o food service o principal canal de distribuição para a empresa $\mathrm{E}$.

0 food service, segmento de refeições fora do lar ou de serviços de alimentação, já se refere a uma consagrada alternativa para o setor frente $o$ maior poder do grande varejo na coordenação dos canais de distribuição. 0 mercado de food service é usualmente estratificado em empresas atuantes nos segmentos de bares, restaurantes, padarias, lanchonetes, fast foods, delivery, lojas de conveniência, catering (fornecimento de comida e bebidas para um grande número de pessoas em festas, casamentos etc.), cozinhas industriais e o segmento "institucional", referente a escolas e hospitais.

0 food service vem apresentando crescimento 50\% maior do que as taxas observadas no varejo alimentício tradicional (grandes redes varejistas), isso se justifica pelo fato de a população economicamente ativa, principalmente nos grandes centros urbanos, recorrer, cada vez mais, à refeições diárias fora do lar (Associação Brasileira das Indústrias da Alimentação, 2009). De fato, a distribuição de alimentos industrializados via food service cresceu a uma média anual de 12,4\% contra $8,7 \%$ do varejo tradicional entre os anos de 1998 e 2008. Esse crescimento do food service estimulou a criação de departamentos específicos dedicados ao atendimento do setor em grandes nomes da indústria brasileira (Associação Brasileira das Indústrias da Alimentação, 2009) - movimento declarado pelos gestores das empresas C e B. No Brasil, $22 \%$ das vendas de alimentos já são distribuídos via food service, enquanto na Europa e nos EUA esses valores são de $40 \%$ e 50\%, respectivamente. Isso revela um segmento com grande potencial de expansão particularmente no mercado brasileiro
(Associação Brasileira das Indústrias da Alimentação, 2009), conforme também evidenciado no estudo exploratório conduzido (vide Tabela 2).

\subsection{Quinto resultado: a atratividade do marketing direto}

Por fim, os resultados sugerem que a busca da indústria de alimentos da atenuação do maior poder comparativamente do grande varejo se revela, ainda, na operacionalização de um canal extremado: as vendas diretas, ou marketing direto.

Apesar de percentuais modestos comparativamente à representatividade dos demais canais, conforme dados expostos na Tabela 2, duas das empresas analisadas no estudo exploratório (empresas C e D) conciliam a comercialização de seus produtos também por meio das vendas diretas. "Inovação na gestão de canal", conforme fala dos gestores entrevistados de ambas as empresas, com grande potencial de crescimento dadas as condições econômicas (brasileiras e mundiais) e as mudanças no comportamento do consumidor.

Kotler (2000) define marketing direto como a atividade de comercialização de bens e serviços exercida pelos produtores e fabricantes, muitas vezes gerenciada por malhas de revendedores, diretos ou indiretos, sem a atuação dos membros intermediários de canal, em particular dos varejistas.

A World Federation of Direct Selling Associations - WFDSA (2014) classifica essa modalidade de canal como um sistema de comercialização de bens de consumo e serviços diferenciados, baseado no contato pessoal entre vendedores e compradores, fora de um estabelecimento comercial fixo. A Associação Brasileira de Empresas de Vendas Diretas - ABEVD (2011) classifica esse canal como "vendas por relacionamento", em virtude de a comercialização ocorrer em círculos sociais, fora de estabelecimentos comerciais fixos.

0 contato direto com o público alvo, consumidor final, abre a oportunidade de estabelecer um relacionamento duradouro com o cliente por parte do produtor/fabricante, o que pode representar uma vantagem competitiva sustentável (Rodrigues et al., 2007). Bird (2000) destaca que a utilização do marketing direto permite isolar o cliente como indivíduo, favorecendo a personalização da oferta demandada pelo consumidor, além de construir uma relação de continuidade, o que possibilita a fidelização do cliente.

Segundo dados oficiais divulgados pela Associação Brasileira de Empresas de Vendas Diretas - ABEVD (2011), as vendas diretas constituem um setor cada vez mais relevante para a economia brasileira (quarto país no ranking mundial do setor), respondendo pela 
contribuição fiscal da comercialização de produtos e serviços realizada por milhões de revendedores autônomos. Esse canal movimentou R \$ 25,8 bilhões em 2010, índice 17,2\% superior ao obtido em 2009. Outra característica importante desse canal refere-se à sua contribuição social como fonte geradora de renda e trabalho formal. Em 2011, as vendas diretas teriam representado alternativa de renda para 2,8 milhões de famílias brasileiras, nos mais variados segmentos da economia nacional, como cuidados pessoais, suplementos nutricionais, cuidados do lar, serviços e outros.

\section{Segundo estágio do estudo: análise multicaso da estratégia de múltiplos canais}

Com o interesse de aprofundar-se na escolha organizacional pela estratégia de múltiplos canais, a segunda fase do estudo empírico centrou-se na realização de dois estudos de caso. Os resultados da primeira fase orientaram a escolha das empresas que participariam da continuidade do estudo (condução dos estudos de caso). 0 recorte se deu na experiência das empresas na gestão de canais alternativos, sendo o critério de escolha a presença do marketing direto - conforme um dos resultados obtidos no primeiro estágio do estudo exploratório.

As duas empresas selecionadas (C e D) responderam a um segundo questionário, presencial, estruturado em questões voltadas ao detalhamento das respectivas estratégias de gestão dos canais de distribuição, em geral, e da abordagem do marketing direto, em particular. As entrevistas presenciais foram realizadas nos meses de março e abril de 2011, conduzidas com os mesmos gestores da área de suprimentos que haviam participado do estágio anterior do estudo exploratório.

\subsection{Análise comparada estudo multicaso: por dentro da estratégia de múltiplos canais}

A estrutura da malha de distribuição das duas empresas se assemelha, sendo a distribuição de produtos para as grandes redes, atacados e redes regionais independentes feitas pela própria empresa, enquanto que para os demais canais é conduzida através de distribuidores (vide Figura 1).

Os entrevistados convergem no entendimento de serem as entregas para o grande varejo otimizadas e mais simples de serem gerenciadas, culminando na decisão organizacional delas mesmas fazerem diretamente a distribuição para as grandes redes varejistas. Porém, quanto menor o porte dos pontos

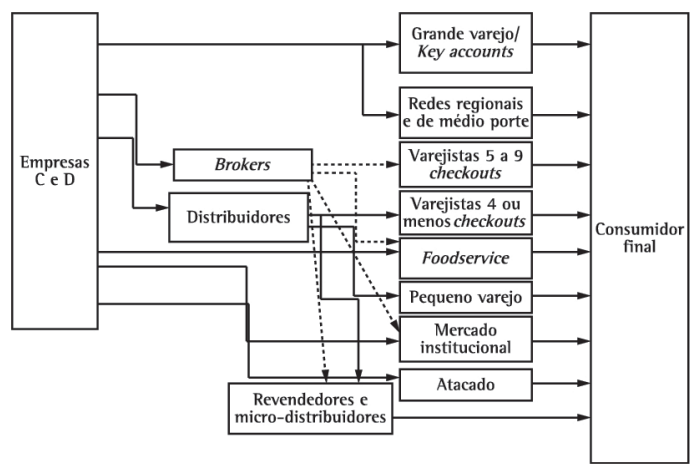

Figura 1. Estrutura dos canais de distribuição das empresas analisadas.

comerciais e menor o volume de negócios, mais onerosa e complicada tende a revelar-se a distribuição, levando as empresas a terceirizarem essa função, caso do atendimento do pequeno e médio varejistas, que se dá por meio dos distribuidores (também chamados na literatura de atacadistas comerciais).

Os entrevistados sinalizam as dificuldades de negociação com as grandes redes varejistas em decorrência do maior poder comparativamente detido pelo grande varejo no controle dos canais de distribuição. Entre outras exigências, ênfase foi dada à "imposição de extensos prazos de pagamento". A esse respeito, situação comparativamente mais "confortável” é encontrada quando das negociações com o pequeno/ médio varejo por meio dos distribuidores, que pagam a vista ou em prazos menores. As empresas conseguem boa margem de lucro nas vendas aos distribuidores, que por sua vez também conseguem boa margem com seus clientes.

Outro ponto de convergência refere-se à percepção da distribuição, por ser a estratégia de canais múltiplos mais complexa e onerosa, justificando decisão organizacional de estruturar esse canal via distribuidores (garantindo maior rentabilidade). Esses agentes são especializados para cada um dos canais, eles compram e revendem os produtos assumindo assim os riscos de perda. Os brokers são um tipo específico de atacadista que atende o médio varejo. Esse mercado tem uma posição comercial mais forte, as lojas têm potencial de crescimento de volume e necessitam de certa competitividade, em consequência as empresas faturam as notas fiscais diretamente, sem intermediação de outras empresas, para essas lojas, restando para os brokers a responsabilidade de promoção nos pontos comerciais, venda e entrega, recebendo uma comissão pelo serviço prestado.

A despeito dessa maior complexidade comparativa, todavia, os gestores entrevistados de ambas as empresas convergem na interpretação de ser o uso 
de canais múltiplos estratégico para a indústria ao possibilitar melhor alcance no mercado (pulverização), concomitantemente a um melhor posicionamento face o maior poder detido pelos grandes varejistas. Corroborando a premissa central desse estudo, a percepção dos entrevistados é que a gestão de múltiplos canais se revela estratégica para a indústria de alimentos justamente por permitir atenuar o maior poder comparativo do grande varejo na coordenação dos canais de distribuição.

Especificamente sobre a atuação nas vendas diretas, as entrevistas convergiram mais uma vez. Entende-se como experiência única de compra, servindo o relacionamento pessoal cliente-revendedor como uma poderosa estratégia de fidelização do cliente. Mesmo podendo resultar em custos mais elevados, devidos às maiores despesas de treinamento e motivação da equipe de vendas, a conveniência oferecida para o consumidor final torna esse mercado comparativamente mais vantajoso, pois além da praticidade de receber a mercadoria em casa, o pagamento não é necessariamente feito a vista. $\mathrm{Na}$ verdade, tipicamente, a transação se dá por meio de relacionamento de confiança, em que o pagamento é realizado mensalmente. Oferta diferenciada que de forma pragmática representa para as empresas oportunidade de aumento de cobertura de mercado. Adicionalmente, os entrevistados ressaltaram ainda ganhos indiretos à imagem das respectivas empresas em termos do papel social desempenhado na geração de emprego e renda a uma malha de revendedores (em muitos casos, a primeira experiência de colocação formal no mercado de trabalho).

A partir dessa análise comparada da estratégia de gestão de canais múltiplos e das vendas diretas, a discussão que segue procura pormenorizar a ação individualizada (retratada na percepção dos gestores entrevistados) de cada uma das duas empresas que foram alvo do estudo multicaso.

\subsection{Empresa C: a estratégia de múltiplos canais}

A empresa mantém relacionamento de longo prazo com as grandes redes varejistas, a saber, Grupo Pão de Açúcar, Carrefour e Walmart, exceto em situações onde haja algum impedimento pontual para execução do contrato. Os contratos podem ser de exclusividade de desenvolvimento de produtos específicos para um cliente, contratos de compra e venda, bonificações comerciais, acordos de marketing ou acordos logísticos.

Entre as vantagens de comercializar com as grandes redes varejistas estão a facilidade na negociação de grandes volumes e os impactos na parcela de mercado, além da facilidade para efetuar ações de trade marketing tais como pontas de gôndola, papafilas, degustações e troca de brindes. Há ganhos devido ao volume, pois é menos custosa a entrega de uma grande quantidade de produtos a um desses clientes, quando comparada a entregas fracionadas.

$\mathrm{Na}$ empresa $\mathrm{C}$ existem equipes dedicadas para $\mathrm{o}$ melhor atendimento de cada um dos clientes chave para cuidar de questões financeiras, da gestão de pedidos e entregas e projetos especiais. Há condições específicas para cada cliente, como, por exemplo, tipo de veículo a ser utilizado, paletização e horário de entrega. São ainda definidas condições como prazo de pagamento, pagamento de bonificações atreladas ao volume de compras/vendas e descontos em casos de escoamento de promoções e produtos sazonais. Em termos de logística, é feito um contrato de pagamento para que o cliente chave efetue o trabalho de armazenagem e distribuição.

A distribuição para as grandes redes, assim como para algumas redes regionais e de médio porte, é feita diretamente pela empresa $\mathrm{C}$ por meio de seus centros de distribuição. Por sua vez, os atacadistas distribuidores que também são abastecidos pelos centros de distribuição efetuam a pulverização dos produtos para o pequeno varejo.

Apesar de a distribuição ser mais complexa para o pequeno e médio varejo, as negociações são mais simples, o pequeno varejista é mais imediatista, com discussões pontuais que buscam descontos ou bonificações, por exemplo. As grandes redes, por sua vez, buscam um plano mais estruturado, as negociações são atreladas ao desenvolvimento da categoria de produtos.

A respeito dos demais canais de distribuição adotados pela empresa, o atacado é atendido diretamente via centro de distribuição, como as grandes redes. Por sua vez, o food service e o mercado institucional podem ser atendidos também via centro de distribuição ou por brokers, de acordo com o volume e a localização.

A empresa $C$ passou a conciliar vendas diretas a partir de 2006, inicialmente na cidade de São Paulo, para atender regiões menos favorecidas (classes C, D e E) e com maior dificuldade de acesso. 0 sistema de vendas está presente em diversas regiões do Brasil, com mais de 135 microdistribuidores (atendidos pelos distribuidores autorizados ou brokers) e participação de aproximadamente 7.700 revendedoras autônomas. A empresa $\mathrm{C}$ tem uma equipe exclusiva responsável pelo abastecimento dos microdistribuidores, elaboração de treinamentos, promoções e programas de fidelização. O programa gera empregos nas comunidades e 
proporciona a inclusão social através da geração de renda. Para os consumidores, o diferencial é receber em casa os produtos da empresa $\mathrm{C}$ em formato de kits, podendo adquirir produtos que não são encontrados nos supermercados de sua cidade, além de economizarem na condução e ter um peso a menos para carregar na sua ida ao supermercado.

\subsection{Empresa D: a estratégia de múltiplos canais}

A empresa usa o termo key accounts para se referir às grandes redes varejistas com atuação no país: Grupo Pão de Açúcar, Carrefour e Walmart. A relação entre a empresa D e as key accounts é formalizada em contratos de suprimento, normalmente com vigência de um ano, sendo de interesse da empresa $\mathrm{D}$ a renovação desses contratos.

Para a empresa D, as vantagens de negociar com as grandes redes varejistas são a garantia de espaço e exposição de produto para grandes massas, a manutenção da participação no mercado e o volume. Esse canal atinge significativa parcela do mercado, funcionando como vitrine para a marca, além de ter um alto giro de produtos. Eles ajudam a pagar os custos fixos e são propaganda, os produtos das marcas não podem ficar fora das gôndolas das key accounts com as quais a empresa tem acordos mundiais.

Em contrapartida, as redes exigem um padrão elevado de nível de serviço, compreendendo frequência de entrega, fill rate (\% do pedido solicitado que é atendido), disponibilidade de produto na gôndola, baixo nível de estoque, exigência de baixo nível de perdas por vencimento. Esses são indicadores que mostram se os pedidos do cliente foram atendidos e se dentro daquilo que foi entregue não faltou produto para o consumidor final. Há ainda exigências comerciais como, por exemplo, margem e investimento em dinheiro.

Além das key accounts, a empresa D também distribui seus produtos diretamente para algumas redes independentes de supermercados e para atacadistas. Por sua vez, a distribuição para as pequenas e médias redes de varejo, assim como para o mercado institucional e revendedores do marketing direto é feita através de intermediários.

A distribuição para o pequeno e médio varejo é feita de duas formas, através de brokers ou de distribuidores autorizados. Os brokers fazem a distribuição para redes de varejo com 5 a 9 checkouts, a empresa parceira é responsável pelo pedido, promoção e transporte, mas as notas fiscais são feitas em nome do broker, sem a participação de outras empresas. A pulverização para o varejo com 4 ou menos checkouts é feita por meio de distribuidores autorizados que fazem a venda e entregam os produtos. As empresas intermediárias têm contratos com a empresa D de exclusividade de área.

0 fornecimento para o pequeno e médio varejo é mais complexo e dispendioso quando comparado ao grande varejo, porém apresenta como vantagens maior rentabilidade, facilidade de negociação e ausência de contratos (apenas quando há acordo de exclusividade).

A empresa D tem um programa específico para distribuição direta para o pequeno e médio varejo. 0 programa foi implantado em duas cidades piloto, porém existe dificuldade para implantá-lo em todo o país devido ao consumo que ainda é muito baixo no Brasil quando comparado com o de outros países. Em outros países da América Latina, por exemplo, o programa apresenta bons resultados, pois, além do maior consumo per capita dos produtos líderes de venda da empresa, os hábitos são diferentes, sendo comum o consumo desses produtos na rua e, consequentemente, a venda em um grande número de pontos comerciais e o alto giro de produtos nesses pontos. Nessas condições, a distribuição direta é bem sucedida, pois uma única parada representa até quatro entregas, dada a proximidade dos pontos comerciais, podendo alcançar um total de 80 entregas diárias. No Brasil, porém, o número máximo alcançado é de 40 entregas por dia, pois em consequência dos pontos comerciais atendidos serem mais distantes uns dos outros o caminhão faz apenas uma entrega em cada parada, o que torna esse processo mais lento e oneroso. Desse modo, torna-se mais custoso copiar no Brasil o sistema implantado em outros paises sem que antes haja mudanças no hábito de consumo do brasileiro e o aumento do consumo per capita.

Outro canal atendido pela empresa D, desde 2003, é o marketing direto. Os revendedores recebem os produtos por meio de distribuidores autorizados e vendem, com seus carrinhos, kits de produtos que são entregues na residência do consumidor final. Os revendedores são autorizados a vender produtos de outras marcas. Esse canal, que existe na cidade de São Paulo, atende o público de baixa renda e por isso tem também caráter social, envolvendo a área de sustentabilidade da empresa D. Também há evidências de que o relacionamento pessoal construído entre vendedor e cliente contribui para o aumento do ticket médio de consumo. Porém pode existir conflito com o pequeno e médio varejo, pois o consumidor deixa de ir à loja física para comprar o produto. Para o consumidor final, o marketing direto é vantajoso, pois nesse caso o pagamento não deve ser feito necessariamente a vista, além da comodidade de receber em casa um kit de produtos feito de acordo com suas preferências. 


\section{Considerações finais, implicações gerenciais e trabalhos futuros}

0 presente artigo aborda a tendência de o elo processador (indústria alimentícia) buscar canais alternativos de distribuição, no intuito de atenuar o expressivo poder exercido pelas grandes redes varejistas. A partir da década de 1990, com o aumento da concorrência, somado ao significativo processo de concentração do setor varejista, ocorre uma alteração no poder de influência (da indústria para o varejo) sobre a coordenação dos canais de distribuição. Os fornecedores (segmento processador e elo rural) passam, então, a ter um significativo grau de dependência das atividades desempenhadas pelo varejo (particularmente os grandes grupos), pois não estar nas gôndolas de uma das grandes redes passou a representar uma perda substancial de mercado.

Os resultados indicam que as empresas analisadas buscam distribuir seus produtos por meio de canais múltiplos, destacando-se a importância do pequeno e médio varejo para o escoamento dos produtos, canal adotado por todas as empresas analisadas, estando sempre entre os de maior significância. Além disso, os resultados sugerem que a indústria vem buscando aumentar a representatividade dos canais alternativos para diminuir o poder de barganha das grandes redes, especificamente investindo no canal de vendas diretas. Destaca-se que o fornecimento para o pequeno e médio varejo é mais complexo e dispendioso quando comparado ao do grande varejo, porém ele apresenta como vantagens maior rentabilidade, facilidade de negociação e usual ausência de contratos formais. Por sua vez, os maiores custos comparativos de gestão do marketing direto também são compensados pela possibilidade de pulverização das vendas e pelos ganhos intrínsecos do relacionamento diferenciado estabelecido com o consumidor.

Tais evidências permitem corroborar a proposição central do estudo. A estratégia de canais múltiplos permite à indústria posicionar-se melhor face ao maior poder detido pelas grandes redes varejistas, graças à possibilidade de maior cobertura de mercado, customização nas vendas e melhor atendimento dos anseios dos consumidores. Tais ganhos revelam-se oriundos da complementaridade da gestão de múltiplos canais, sendo essa uma importante implicação gerencial para as indústrias de alimento. A estratégia de múltiplos canais exige governanças específicas por canal, o que tende a aumentar a complexidade gerencial. Os contratos e as exigências particulares nas negociações com cada um deles são distintos. Por meio das grandes redes varejistas busca-se a exposição da marca, enquanto os demais canais garantem maior rentabilidade.

Em termos de trabalhos futuros, seria interessante explorar outros métodos de pesquisa para verificar o comportamento dos agentes no que diz respeito à estratégia de canais múltiplos. Sugere-se o uso de métodos de pesquisa cuja abordagem seja quantitativa, o que permitiria a generalização estatística dos resultados. Além disso, o trabalho poderia ser feito com diferentes setores produtivos, com o objetivo de verificar se essa estratégia é generalizada ou característica de determinados setores produtivos, como é o caso da indústria alimentícia.

\section{Agradecimentos}

Os autores agradecem à Fundação de Amparo à Pesquisa do Estado de São Paulo (Fapesp), pelo imprescindível apoio financeiro, assim como às empresas analisadas, por terem colocado à disposição todas as informações necessárias. A versão final do artigo beneficiou-se de sugestões de pareceristas anônimos, a quem os autores também agradecem pelas importantes contribuições. Por fim, os autores ainda agradecem ao Center for Organization Studies (CORS), pelo frutífero ambiente de discussões.

\section{Referências}

Associação Brasileira das Indústrias da Alimentação - ABIA. (2009). O Mercado de food service. 2009. Retrieved from http://www.abia.org.br/cfs2009/telas/food-service.asp.

Associação Brasileira de Empresas de Vendas Diretas - ABEVD. (2011). Números do setor. Retrieved from www.abevd. org.br.

Aguiar, D. R. D. (2009). The case of Brazil. In K. W. Stiegert, K. W. Tiegert \& D. H. Kim (Eds.), Structural changes in food retailing: six country case studies (n. 22, chap. 3.). Madison: Food System Research Group (FSRG), Department of Agricultural and Applied Economics, University of Wisconsin-Madison, FSRG Monograph Series.

Aguiar, D. R. D., \& Figueiredo, A. M. (2011). Poder de mercado no varejo alimentar: uma análise usando os preços do estado de São Paulo. Revista de Economia e Sociologia Rural, 49(4). http://dx.doi.org/10.1590/ S0103-20032011000400007

Alcântara, R. L. C. (1999). Sistemas de distribuição e arranjos cooperativos: o caso do atacado brasileiro. Gestão \& Produção, 6(3), 219-232. http://dx.doi.org/10.1590/ S0104-530X1999000300007

Bell, R, Davies, R. \& Howard, E. (1997). The changing structure of food retailing in Europe: the implications for strategy. Long Range Planning, 30(6), 853-861. http:// dx.doi.org/10.1016/S0024-6301(97)00071-X

Berman, B. (1996). Marketing channels. John Willey \& Sons. $663 \mathrm{p}$.

Bird, D. (2000). Bom senso em marketing direto. Sã Paulo: MakronBooks.

Bowersox, D.J., \& Closs, D.J. (2001). Logística empresarial: o processo de integração da cadeia de suprimento. São Paulo: Editora Atlas.

Bowersox, D. J., Closs, D.J., \& Cooper, M. B. (2007). Gestão da cadeia de suprimentos e logística (2. ed.). Rio de Janeiro: Elsevier.

Coughlan, A., Anderson, E., Stern, L., \& El-Ansary, A. (2001). Marketing channels. New Jersey: Prentice Hall. 
Dobson, P. W. (2003). Buyer power in food retailing: the European experience. Conference on Changing Dimensions of the Food Economy: Exploring the policy issues. Hague.

Farina, E. M. M. Q. \& Nunes, R. (2002). A evolução do sistema agroalimentar e a redução de preçospara o consumidor: o efeito de atuação dos grandescompradores. Programa de estudos dos negócios do sistemaagroindustrial PENSA, São Paulo: PENSA/FIA/ FEA/USP.

Faulin, E. J. \& Azevedo, P. F. (2003). Distribuição de hortaliças na agricultura familiar: uma análise das transações. Informações Econômicas, 33(11).

Fleury, P. F. (1999). Supply chain management: conceitos, oportunidades e desafios da implementação. Revista Tecnologística, 4(30), 25-32.

Gurdjian, P., Kerschbaumer, G., Kliger, M. \& Waterous, J. (2000). Bagging Europe's groceries. The McKinsey Quarterly. Retrieved from http://www.mckinseyquarterly. com/Bagging_Europes_groceries_808.

Hutchins, R. (1997). Category Management in the food industry: a research agenda. British Food Journal, 99(5), 177-180. http://dx.doi.org/10.1108/00070709710175088

Kamio, G. (2010). A válvula do varejo. EmbalagemMarca, 132, 12-17.

Kotler, P. (1972). Marketing management: analysis, planning, and control (2nd ed.). Prentice-Hall.

Kotler, P. (2000). Marketing management (10th ed.). Prentice Hall,

Marques, E. F., Alcantara, R. L. C. (2004). 0 uso da ferramenta gerenciamento de categoria na gestão da cadeia de suprimentos: um estudo multicaso. Gestão \& Produção, 11(2):153-164.

Marsola, C. (2008). Carrefour lidera ranking dos 20 maiores supermercados, diz Abras. Folha de S. Paulo, São Paulo. Retrieved from http://www1.folha.uol.com.br/ folha/ dinheiro/ult91u379230.shtml.

Mintel (2006). Report: own-label food and drink. Market Intelligence. 2006.

Noll, R.G. (2005). Buyer power and economic policy. Stanford Institute for Economic Policy Research (SIEPR). Discussion Paper No. 04-08.

Paula, V. A. F., Silva, A. L. \& Piato, E. L. (2012). Estratégia de marcas próprias no varejo supermercadista: um estudo comparativo entre Brasil e Inglaterra. Produção, 23(1), 6679.http://dx.doi.org/10.1590/S0103-65132012005000025

Pêgo, L. S. (2009). Impactos da estratégia de produto no canal de distribuição: estudo multicaso sobre o relacionamento entre a indústria avícola e o varejo (Dissertacão de mestrado). Universidade Federal de São Carlos, São Paulo.
Reardon, T., Henson, S. \& Berdegué, J. (2007). Proactive fast-tracking diffusion of supermarkets in developing countries: implications for market institutions and trade. Journal of Economic Geography, 7(4), 399-431. http:// dx.doi.org/10.1093/jeg/lbm007

Reardon, T., Timmer, P. \& Minten, B. (2010). Supermarket revolution in Asia and emerging development strategies to include small farmers. PNAS early edition. http:// dx.doi.org/10.1073/pnas.1003160108

Rodrigues, J. B. D., Rodrigues, M. A. \& Oliveira, P. A. (2007). Marketing direto: uma ferramenta indispensável para o sucesso em vendas. Maringá Management: Revista de Ciências Empresariais, 4(1), 27-34.

Rosenbloom, B. (2004). Marketing channels: a management view (7th ed.). International Thomson Press.

Salles, F. (2010). Lojas pequenas são as que mais crescem. Hipermercados caem. Supermercado Moderno, São Paulo. Retrieved from http://www.sm.com.br/publique/ cgi/cgilua. exe/sys/start.htm?infoid $=8834$ Ctsid $=5$.

Silva, V. L. S., Azevedo, P. F. \& Neves, M. F. (2012a). Franchising, valor de marca e canais de distribuição. In V. L. S. Silva \& P. F. Azevedo (Orgs.), Teoria e prática do franchising: estratégia e organização de redes de franquias (cap. 1.). São Paulo: Atlas.

Silva, V. L. S., Porto, A. S., Sanches, I. S., Schinaider, P. S. B., Corvacho, T. C., Franco, N. F. (2012b). Franchising como canal alternativo de comercialização. In V. L. S. Silva \& P. F. Azevedo (Orgs.), Teoria e prática do franchising: estratégia e organização de redes de franquias (cap. 5.). São Paulo: Atlas.

Silva, V. L. S., Rodrigues, F., Sannomya, J., Peres, L. \& Corvacho, T. (2009). Integração vertical comoestratégia de apropriação de valor: um estudoexploratório no canal de distribuição de produtosagrícolas. Gestão \& Produção, 16(1). http://dx.doi.org/10.1590/S0104530X2009000100005

Souza, R. C. \& Scur, G. (2011). As transações entre varejistas e fornecedores de frutas, legumes e verduras na cidade de São Paulo. Produção, 21(3), 518-527. http://dx.doi. org/10.1590/S0103-65132011005000040

Souza, R. C. (2001). As estruturas de governança dos canais de comercialização de frutas, legumes e verduras no município de São Carlos, Estado de São Paulo. Informações Econômicas, 31(11), 26-31.

Stern, L., El-Ansary, A. 1. \& Coughlan, A. (1996). Marketing channels (5th ed.). Prentice-Hall.

Revista SuperHiper. (1996). Serviços de marketing. Revista SuperHiper, set.

World Federation of Direct Selling Associations - WFDSA. (2014). What is Direct Selling? Retrieved from http:// www.wfdsa.org/about_dir_sell/?fa=whatisds.

\title{
Strategy management of multi-channel distribution: a study in the Brazilian food industry
}

\begin{abstract}
This article aims to investigate the management of a multiple-channel distribution by relevant Brazilian food industries. An exploratory study was conducted in two stages: distance interviews with supply chain managers (six companies), followed by face-to-face interviews (in two companies selected from the initial sample). The study highlights the food industry's search to distribute its products through a combination of two retail formats (large and small/medium) with at least one more channel, with a positive trend in the use of alternative formats, including direct marketing. Corroborating the central premise of the study, the field research indicates that the management of multiple channels reveals a strategic decision to the food industry, helping it better address the comparatively large power of large retailers. Additionally, the food industry can potentially increase market coverage and sales customization and provide better service for the clients.
\end{abstract}

\section{Keywords}

Strategy. Distribution channel. Power. Retail. Food industry. 